\title{
A child with intellectual disability and dysmorphism due to complex ring chromosome 6: identification of molecular mechanism with review of literature
}

\author{
Frenny Sheth ${ }^{1 *}$ D, Thomas Liehr ${ }^{2}$, Viraj Shah ${ }^{1}$, Hillary Shah ${ }^{1}$, Stuti Tewari ${ }^{1}$, Dhaval Solanki ${ }^{3}$, Sunil Trivedi ${ }^{1}$ \\ and Jayesh Sheth ${ }^{1}$
}

\begin{abstract}
Background: Ring chromosome $6(r(6))$ is a rare disorder that mainly occurs as a 'de novo' event. Nonetheless, a wide phenotypic spectrum has been reported in $r(6)$ cases, depending on breakpoints, size of involved region, copy number alterations and mosaicism of cells with $r(6)$ and/or monosomy 6 due to loss of $r(6)$.

Case presentation: An 11-year-old male was referred with developmental delay, intellectual disability and microcephaly. Physical examination revealed additionally short stature and multiple facial dysmorphisms. Banding cytogenetic studies revealed a karyotype of mos 46,XY,r(6)(p25.3q27)[54]/45, XY,-6[13]/46,XY,r(6)(::p25.3 $\rightarrow$ q27::p25. $3 \rightarrow q 27::)[13] / 46, X Y[6] / 47, X Y, r(6)(p 25.3 q 27) \times 2[2] d n$. Additionally, molecular karyotyping and molecular cytogenetics confirmed the breakpoints and characterized a 1.3 Mb contiguous duplication at 6p25.3.

Conclusion: The present study has accurately identified copy number alterations caused by ring chromosome formation. A review of the literature suggests that hemizygous expression of TBP gene in 6q27 qter, is likely to be the underlying cause of the phenotype. The phenotypic correlation and clinical severity in $r(6)$ cases continue to remain widely diverse in spite of numerous reports of genomic variations.
\end{abstract}

Keywords: Molecular karyotyping, Molecular cytogenetics, Haploinsufficiency, Ring chromosome, R(6)

\section{Background}

Ring chromosome $6(\mathrm{r}(6))$ is an exceedingly rare disorder, first described in 1973 by Moore et al. [1]. Since then, $>30$ patients with this condition have been reported [2]. Formation of ring chromosomes usually occurs due to breaks in the terminal portions of both the chromosome arms, followed by the fusion of broken ends. Alternatively, they can be formed by the union of subtelomeric sequences or telomere-telomere fusion with no deletion, resulting in a complete ring chromosome. Such complete rings without apparent significant loss of genetic material have been described in individuals with normal phenotypes [3]. Other mechanisms for

\footnotetext{
* Correspondence: fshethad1@googlemail.com

${ }^{1}$ FRIGE's Institute of Human Genetics, FRIGE House, Jodhpur Gam Road,

Satellite, Ahmedabad 380009, India

Full list of author information is available at the end of the article
}

ring chromosome formation, like terminal deletions, and/ or contiguous inverted duplication due to an inv-dup-del rearrangement/s have also been proposed in the literature [4-6], also recently chromothripsis has been attributed as a possible reason for such cases [7].

Even though being rare, a wide spectrum of phenotypic variability is observed in all cases of autosomal ring chromosomes. Congenital heart defects, intellectual disability, microcephaly, facial dysmorphism, failure to thrive and various abnormalities in the ocular, auditory and central nervous systems are frequently detected [8].

In this study, a mosaic $\mathrm{r}(6)$ in a clinically abnormal, 11-year-old male was characterized in detail and compared with cases from the literature to share some new insights into the genotype-phenotype correlations.

(c) The Author(s). 2018 Open Access This article is distributed under the terms of the Creative Commons Attribution 4.0 International License (http://creativecommons.org/licenses/by/4.0/), which permits unrestricted use, distribution, and 


\section{Case presentation}

An 11-year-old male was referred for further diagnostics due to developmental delay, intellectual disability and microcephaly. He was the first child born to apparently healthy non-consanguineous parents. The mother had an uneventful pregnancy with no history of prenatal exposure to alcohol, drug or tobacco. Though his siblings (7-year brother and 3 years old sister) were phenotypically normal, his paternal cousin-sister was microcephalic and mentally challenged. No investigations were carried out in the affected cousin-sister.

The proband was born by normal vaginal delivery. The birth weight was $1.5 \mathrm{~kg}$ and head circumference was $33 \mathrm{~cm}$. Apgar score at birth was within the normal range. The patient was sitting without support at around 1.5 years. He could stand with support by 2 years and independent walking at 2.5 years. His speech development was delayed. He was not able to speak sentences and could not achieve proper bowel and bladder control even at the time of presentation (11 years). His height and weight were $108 \mathrm{~cm}$ and $14.5 \mathrm{~kg}$ respectively (below 10th centile); head circumference (OFC; Occipital Frontal Circumference) was $42 \mathrm{~cm}$ (below 3rd centile). The proband portrayed short stature and microcephaly with developmental delay. The facial dysmorphism showed long face, small chin, large protruding ears, slightly upturned eyes, sparse eyebrows, large bulbous nose and thin upper lip (Fig. 1a and b). Speech delay, penile chordee and sacral dimple were also noted during physical examination. His respiratory, cardiovascular and abdominal examinations were unremarkable. CNS examination showed intellectual disability, delayed language development and hyperactivity. His speech and cognitive development was more delayed than his motor milestones, and academic performance was very poor. His serum TSH (thyroid stimulating hormone) and GH (growth hormone) levels were normal. Magnetic resonance imaging (MRI; performed at an age of 10 years) showed demyelination in both frontal and parietal lobes (Fig. 2). Ultrasonography of abdomen and pelvis were normal, as were echocardiogram and ophthalmologic examinations.

Sample collection and written informed consent was obtained according to the need of the institutional ethics committee in accordance with Helsinki declaration. Chromosome analysis of the patient was performed with $72 \mathrm{~h}$ lymphocyte culture and standard GTG-banding. The karyotype was interpreted according to the International System for Human Cytogenetic Nomenclature (ISCN 2016) [9] as mos 46,XY,r(6)(p25.3q27)[54]/ 45,XY,-6[13]/46,XY,r(6)(::p25.3 $\rightarrow$ q27::p25.3 $\rightarrow$ q27::)[13]/ 46,XY[6]/47,XY,r(6)(p25.3q27)×2[2]dn (Fig. 3).

Karyotype of the parents was normal, confirming a 'de novo' origin of the $\mathrm{r}(6)$. Further analysis was carried out by molecular karyotyping using Affymetrix CytoScan ${ }^{\text {Tx }} 750 \mathrm{~K}$ array. Data was analyzed using Chromosome Analysis Suite (ChAS) and revealed: arr [GRCh37] 6pterp25.3(156,974_ 665,234)x1,6p25.3(668,700_1,929,528)x3,6q27qter(170,466,51 $\left.3 \_170,914,297\right) \times 1$. In other words, there was a partial terminal monosomy of overall $508 \mathrm{~kb}$ in $6 \mathrm{p} 25.3$ followed by a $1.3 \mathrm{Mb}$ contiguous duplication in $6 \mathrm{p} 25.3$ and $448 \mathrm{~kb}$ terminal deletion in 6q27 (Fig. 4). These results were
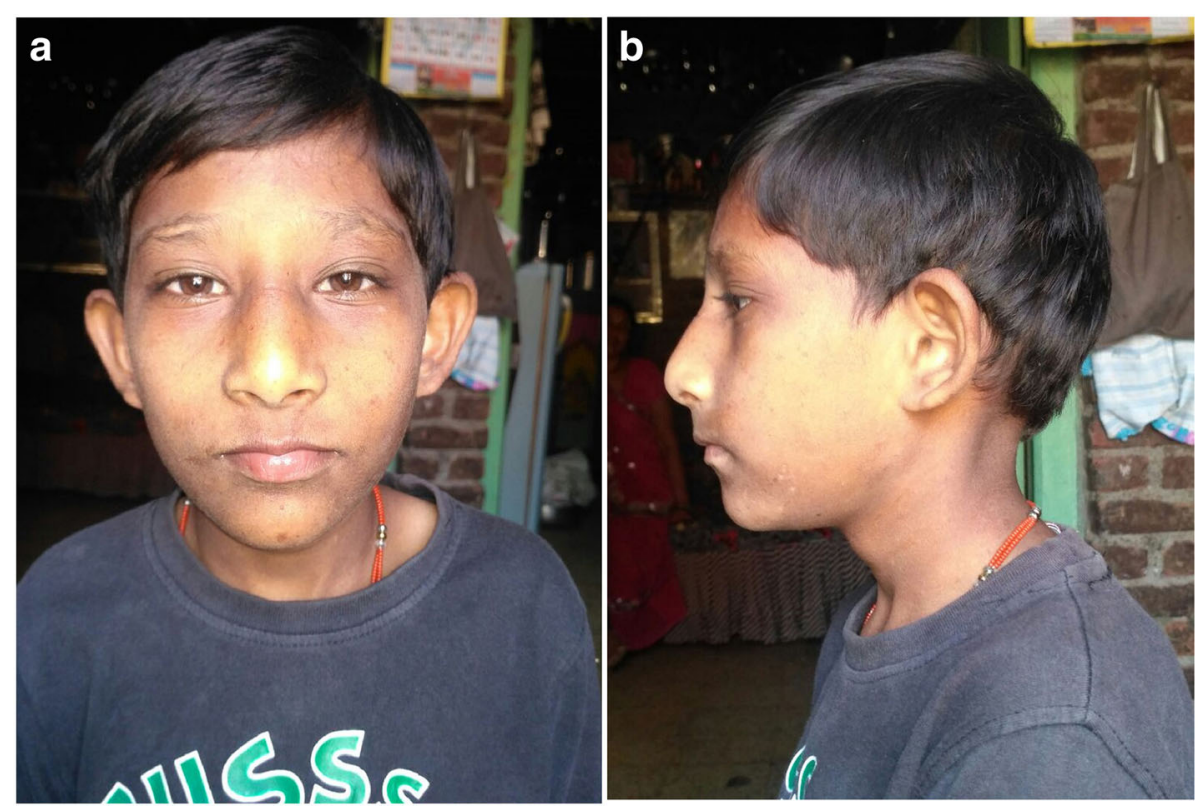

Fig. $1 \mathbf{a}$ and $\mathbf{b}$ Facial phenotype of the proband 


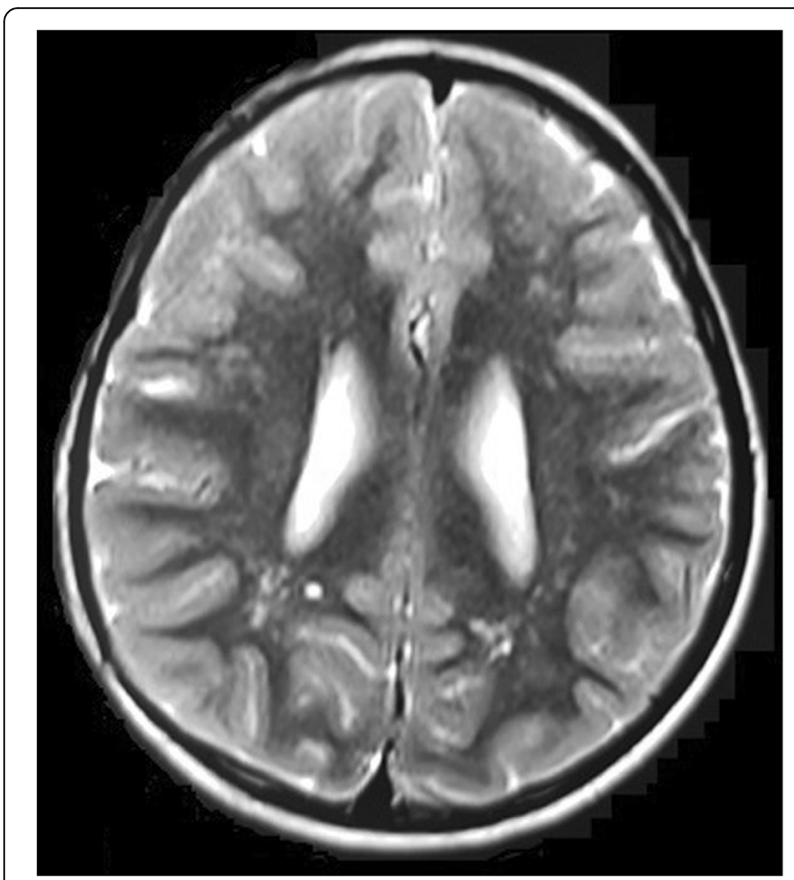

Fig. $2 \mathrm{MRI}$ picture depicting bilateral frontal and parietal lobe white matter changes

confirmed by fluorescence in situ hybridization (FISH) using commercially available subtelomeric probes for 6 pter and 6 qter. The duplicated region in $6 \mathrm{p} 25.3$ could not be confirmed by another method due to lack of corresponding locus-specific probes. The dicentric nature of double ring was thus established by a centromeric probe (Fig. 5).

\section{Discussion and conclusions}

Ring chromosome 6 is a rare event, that generally occurs as a 'de novo' event. Inheritance of ring chromosomes is quite infrequent since it is unstable during cell division with a possible loss of the ring during meiosis. Moreover, ring chromosome carriers may be infertile due to the chromosomal alteration.

Postnatal growth failure and microcephaly are the leading features of any autosomal ring chromosome; also they tend to show dynamic mosaicism, as observed in the present case. Patients with $r(6)$ syndrome frequently present with growth retardation, facial dysmorphism and microcephaly. The additional clinical features of the present case can most likely be attributed to the cryptic duplication event in the $r(6)$.

Major features associated either with $6 p$ or $6 q$ terminal deletions include defects of the anterior eye-chamber development, hearing loss, heart malformations, hypertelorism, mid-face hypoplasia, low set ears, developmental delay, intellectual disability, hypotonia, seizures, facial dysmorphism, and short neck $[10,11]$. Most of these findings are analogous to that noted in the proband under report which suggests that the phenotypic variability and severity may partially be attributed to existence and instability of the ring. Several mechanisms for such instability are proposed in the literature, without plausible explanation $[3,12]$. Further, the severity of the phenotype is hypothesized to be related to the size of the deletion. Microcephaly, facial dysmorphism and cardiac abnormalities seem to be more prevalent in the patients with single cell line anomaly; conversely, growth retardation, intellectual disability and demyelination of frontal and parietal lobes were additional anomalies that were more frequent with multiple cell lines.

To establish genotype/phenotype correlations for $\mathrm{r}(6)$, we compared the clinical features of the case under report to previously reported cases of $\mathrm{r}(6)$ (Table 1; Fig. 6) and explored the deleted and duplicated regions for morbid genes, using OMIM database and DECIPHER (https://decipher.sanger.ac.uk/).

The deleted $508 \mathrm{~kb}$ subtelomeric region from 6 pter to 6p25.3 contains 4 annotated genes: DUSP22, IRF4, EXOC2, HUS1B; IRF4 (*601900) being the only OMIM morbid gene. Interferon regulatory factor 4 (IRF4) is a transcription factor essential for the development of $\mathrm{T}$ helper 2 (Th2), Th17 and Th9 cells, whose allelic variant influences variation in skin/hair/eye pigmentation 8 . Dysregulation of IRF4 is associated with lymphoid malignancies [29].

The duplicated segment of $1.3 \mathrm{Mb}$ at $6 \mathrm{p} 25.3$ was larger in size and contained more relevant OMIM genes-three

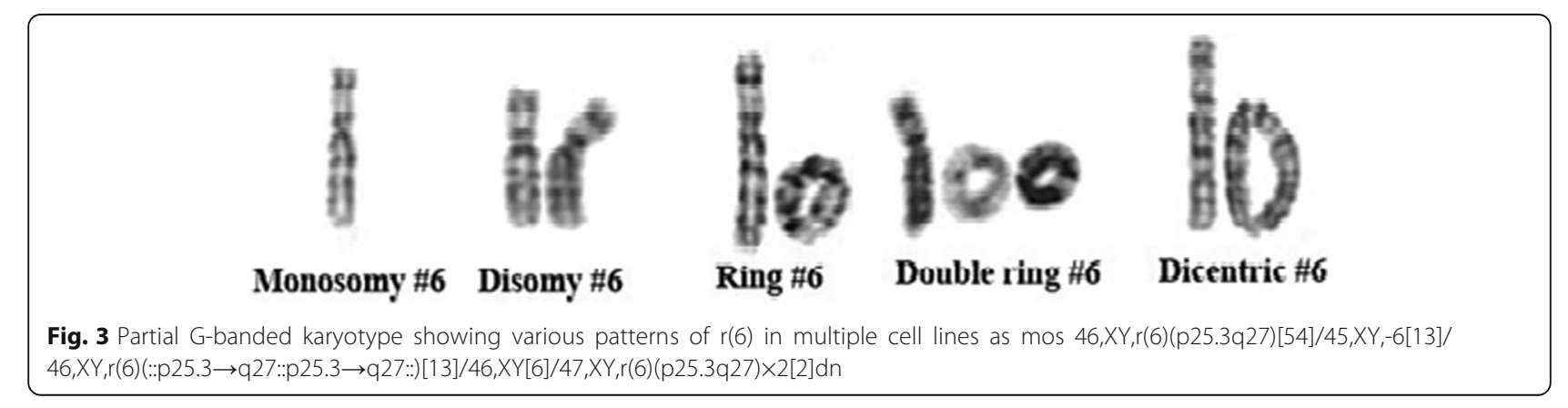




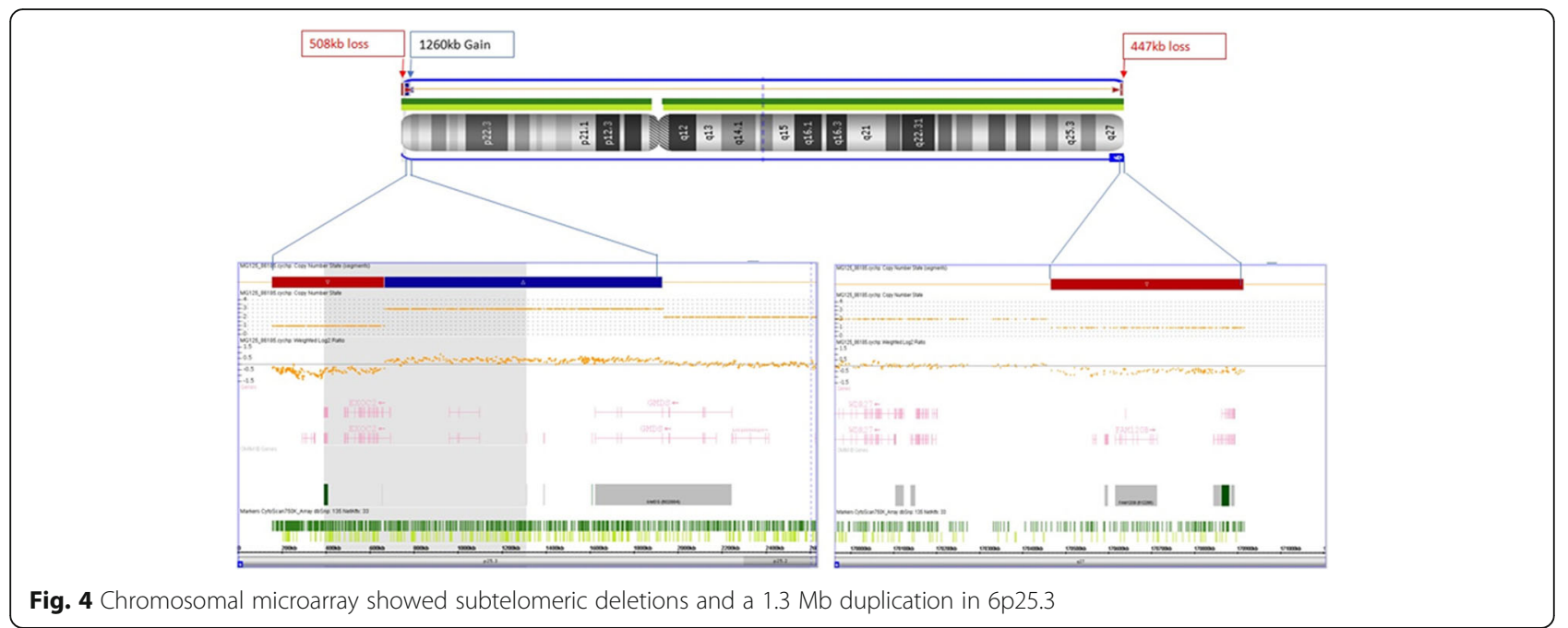

copies each of EXOC2, LOC285768, FOXQ1, FOXF2, FOXC1, GMDS, FOXCUT; FOXC1 being the only morbid gene amongst them. Mutations in Forkhead box C1; (FOXC1; "601090) has been associated with phenotypes like Anterior segment dysgenesis 3 and Axenfeld Reigen syndrome type 3 . Nishimura et al. [30] in their study demonstrated that haploinsufficiency in addition to the mutations as well as increased gene dosage may cause anterior chamber defects of the eye. Later, Lehman et al. [31] reported an association between interstitial 6p25 duplications involving FOXC1 gene and ocular developmental abnormalities and glaucoma. Ophthalmologic examination in the patient under report did not reveal any abnormality and possibly point towards a less likely role of an extra copy of FOXC1 alone in the ophthalmological manifestations in such patients.

Apart from ocular manifestations, mutations and haploinsufficiency of FOXC1 gene have also been speculated to be implicated in cardiac abnormalities [2, 32]. However, there seem to be no reports to suggest for duplication. The patient under report had normal echocardiography findings. There is a paucity of data on the pathological manifestations of distal 6p duplication. Qi et al. elaborated on the same in 2015 study and concluded that copy number gain of this particular region is likely benign or triploinsensitive [33].

A terminal deletion $(448 \mathrm{~kb}$ ) was detected (from $6 \mathrm{q} 27$ to 6qter) that encompass LOC154449, DLL1, FAM120B, MIR4644, PSMB1, TBP, PDCD2 OMIM annotated genes. Amongst them, TATA-binding protein (TBP), a general transcription factor associates with aggregates in several polyglutamine disorders; is the only gene with a pathogenic potential [34]. A reasonable number of studies have postulated $T B P$ as a potential candidate gene responsible for the phenotype of patients with subtelomeric $6 q$ deletions, irrespective of the size of terminal deletion [35, 36]. Moreover, a study [37] has reported a 'de novo' missense mutation in the chromosome 6 open reading frame 70 (C6orf70) gene in 1/14 (7.1\%) patient with periventricular nodular heterotopia, developmental delay and epilepsy through whole exome sequencing. In addition, the authors silenced C6orf70 and two additional genes (phf10 and Dll1) in the developing rat neocortex and suggested that C6orf70 plays a major role

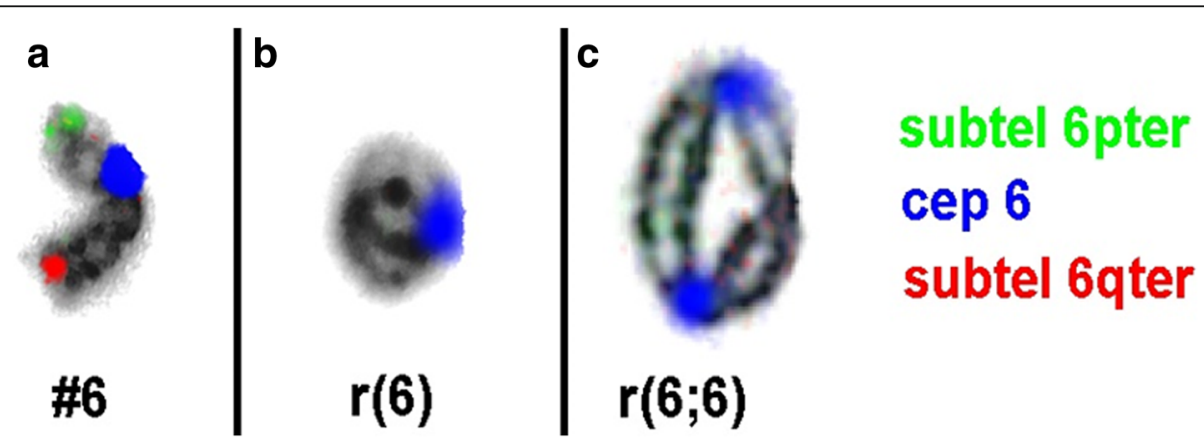

Fig. 5 FISH study showed a) 3 signals (green, blue and red) that confirm an intact chromosome 6. b) single signal (blue) on r(6) confirm subtelomeric deletions at both the arms. c) Two signals (blue) confirm two centromeres present in a dicentric ring 


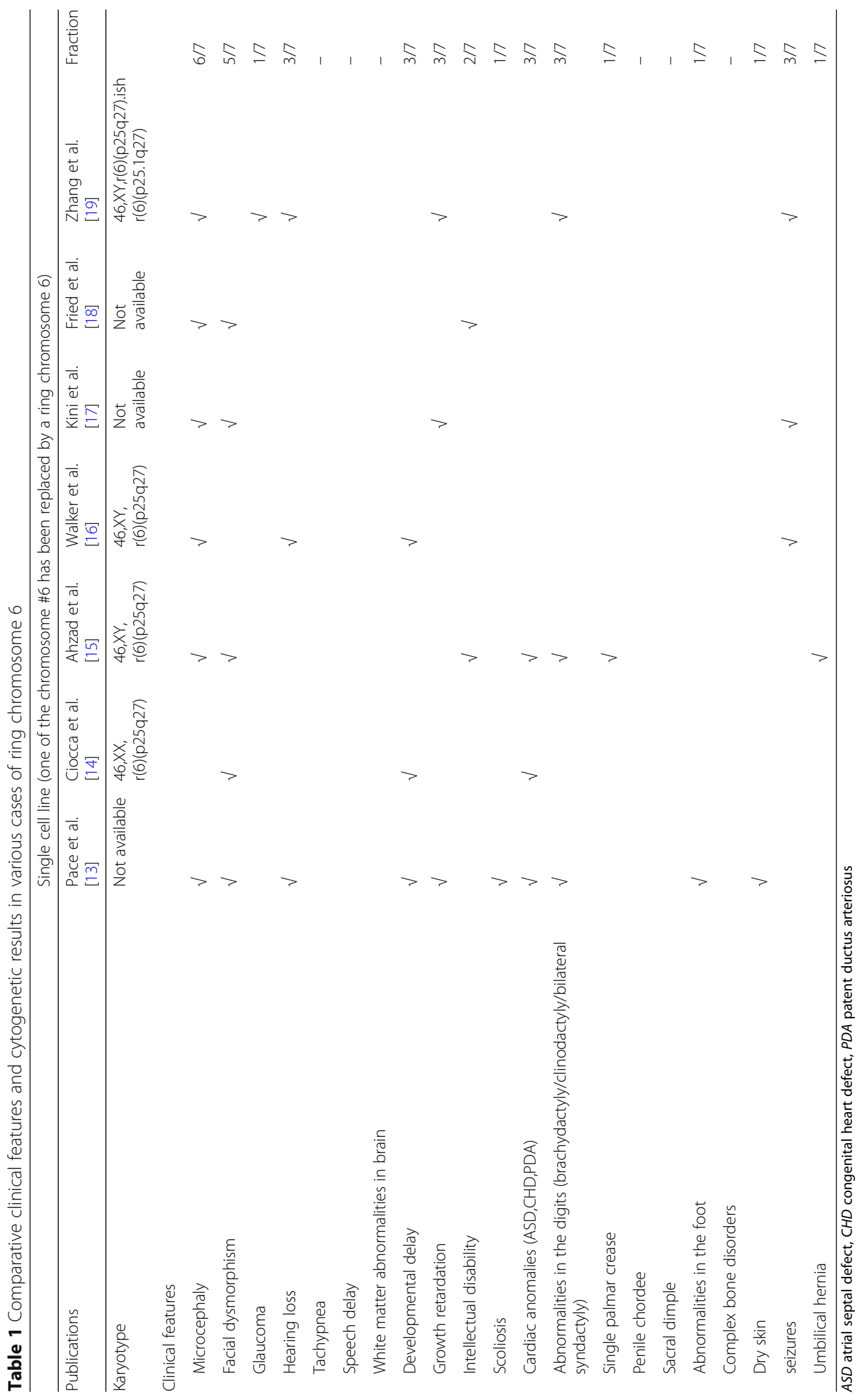




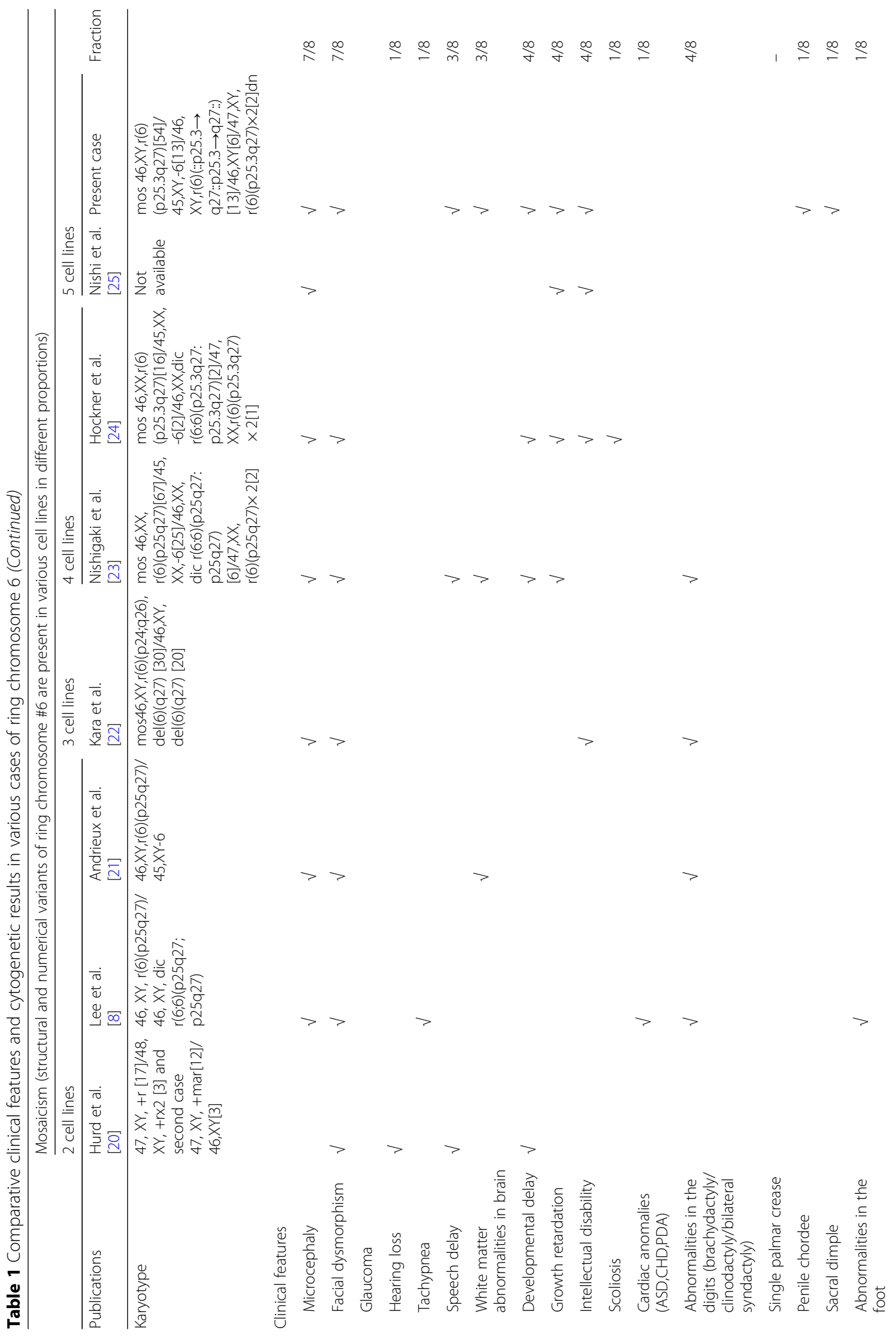




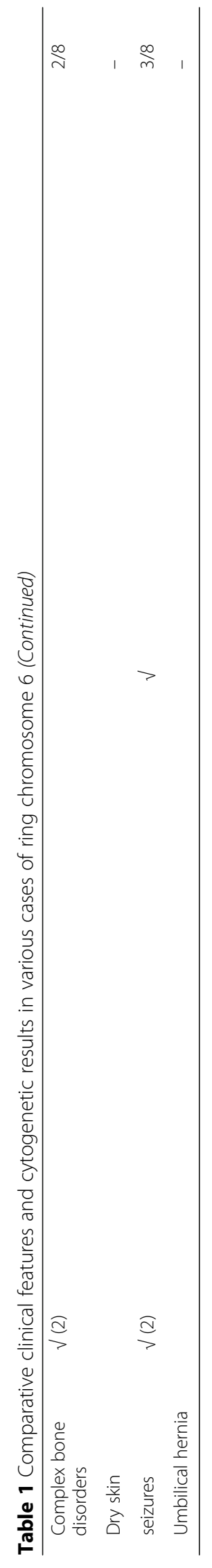




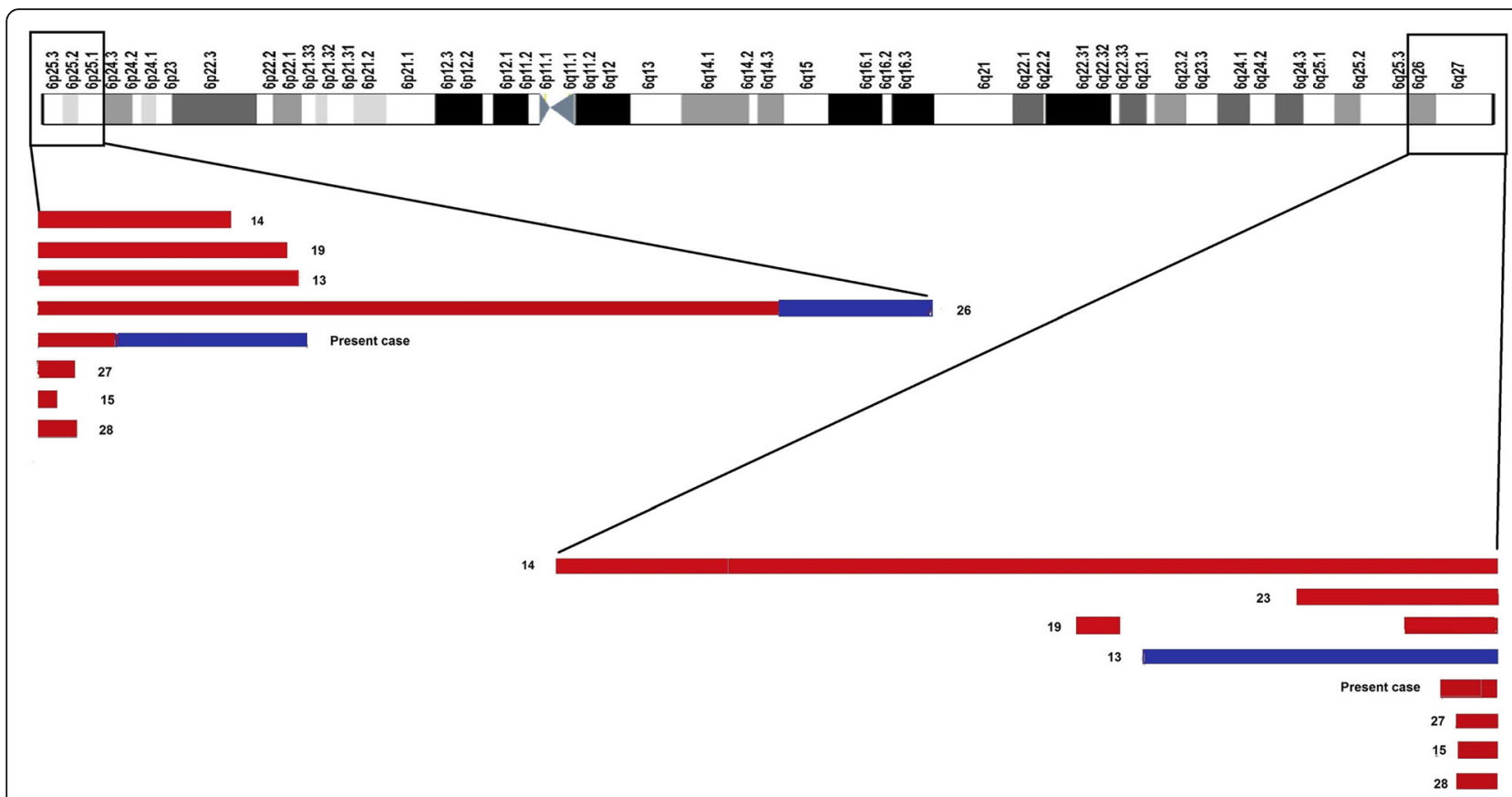

Fig. 6 Schematic representation of chromosome 6 reveal deleted and/or duplicated genomic regions with previously reported cases with $r(6)$. Breakpoint distribution is based on the molecular cytogenetic data seen in cases having $r(6)$. The deleted (red) and duplicated regions (blue) are shown according to a scale of $1 \mathrm{Mb}=3.2 \mathrm{~cm}$. Numerical number mentioned by bars indicate the correcponding references [26-28]

in the control of neuronal migration and its haploinsufficiency or mutation causes periventricular heterotropia.

Developmental delay, intellectual disability, dysmorphism, seizures, dimpling of elbows and knees are some of the main features noted in such patients. Most of the above mentioned clinical features were also seen in our patient, raising a strong possibility pointing towards the hemizygous expression of TBP might be implicated in the causation of the phenotype. Apart from these, the developmental delay, growth stunting and mild facial dysmorphism observed in the proband can also be attributed partially to the mitotic instability of the ring chromosome as the source of continuous production of secondary aneuploid cells [3, 25]. There is still a dearth of literature on ring chromosome 6 and therefore, further studies are advocated to understand the role of genes influencing such genotype-phenotypic presentations.

\section{Abbreviations}

DLL1: Delta like canonical notch ligand 1; DUSP22: Dual specificity phosphatase 22; EXOC2: Exocyst complex component 2; FAM120B: Family with sequence similarity 120B; FISH: Fluorescence in situ hybridization; FOXC1: Forkheadbox C1; FOXCUT: FOXC1 upstream transcript; FOXF2: Forkheadbox F2; FOXQ1: Forkhead box protein Q1; GMDS: GDPmannose 4,6-dehydratase; HUS1B: HUS1 checkpoint clamp component B; IRF4: Interferon regulatory factor 4; ISCN: International System for Human Cytogenetic Nomenclature; MIR4644: MicroRNA 4644; PDCD2: Programmed cell death 2; PSMB1: Proteasome subunit beta type-1; r(6): Ring chromosome 6; SNP: Single nucleotide polymorphism; TBP: TATA-binding protein

\section{Acknowledgements}

We would like to express our sincere thanks to Dr. Krati Shah for critical reading. We are grateful to the family of the patient for their kind cooperation and permission. We acknowledge the Gujarat State Biotechnology Mission (GSBTM) [Grant no.: GSBTM/MD/PROJECTS/SSA/505/4865/2016-17]

for partly supporting the work.

\section{Funding}

This work is partly supported by Gujarat State Biotechnology Mission (GSBTM) [Grant no:: GSBTM/MD/PROJECTS/SSA/505/4865/2016-17]. The funding agency was not directly or indirectly involved in the study design, specimen collection, analysis, interpretation and preparation of the manuscript.

Availability of data and materials

Data sharing not applicable to this article as no datasets were generated or analyzed during the current study.

\section{Authors' contributions}

Conceived and designed the experiments: FS. Clinical analysis: DS. Cytogenetic and Molecular analysis: FS and TL. Wrote the first draft of the manuscript: HS, VS, ST. Made critical revisions and approved final version: JS, ST. All authors reviewed and approved of the final manuscript.

Ethics approval and consent to participate

- Present case under submission has been approved by the institutional ethics committee [FRIGE's Institute of Human Genetics] wide approval number FRIGE/IEC/15/2016 dated 16th March, 2016. This process is in accordance with the Helsinki declaration.

- An informed consent was obtained from the parents before enrolling for the investigations [This was in accordance with the requirement of the institutional ethics committee].

- An informed consent for publication was also obtained from the parents [This was in accordance with the need of the institutional ethics committee]. 


\section{Consent for publication}

Written informed consent was obtained from patient's parents for publication of their clinical details. A copy of the written consent is available for review.

\section{Competing interests}

The authors declare that they have no competing interests.

\section{Publisher's Note}

Springer Nature remains neutral with regard to jurisdictional claims in published maps and institutional affiliations.

\section{Author details}

'FRIGE's Institute of Human Genetics, FRIGE House, Jodhpur Gam Road, Satellite, Ahmedabad 380009, India. ${ }^{2}$ University Clinic Jena, Institute of Human Genetics, Am Klinikum 1, 07747 Jena, Germany. ${ }^{3}$ Mantra Child Neurology \& Epilepsy Hospital, 3rd floor, Oarnate complex, Kalubha road, Kalanala, Bhavanagar 364001, India.

\section{Received: 4 August 2018 Accepted: 21 September 2018}

\section{Published online: 11 October 2018}

\section{References}

1. Moore CM, Heller RH, Thomas GH. Developmental abnormalities associated with a ring chromosome 6. J Med Genet. 1973;10:299-303.

2. Zhang R, Chen X, Li P, Lu X, Liu Y, Li Y, et al. Molecular characterization of a novel ring 6 chromosome using next generation sequencing. MolCytogenet. 2016;9:33. https://doi.org/10.1186/s13039-016-0245-9.

3. Yip MY, Genetics Laboratory SEALS. Autosomal ring chromosomes in human genetic disorders. In: TransIPediatr; 2015. https://doi.org/10.3978/j. issn.2224-4336.

4. Seghezzi L, Maraschio P, Bozzola M, Maserati E, Tupler R, Marchi A, et al. Ring chromosome 9 with a 9p22.3-p24.3 duplication. Eur J Pediatr. 1999;158:791-3.

5. Knijnenburg J, van Haeringen A, Hansson KB, Lankester A, Smit MJ, Belfroid $\mathrm{RD}$, et al. Ring chromosome formation as a novel escape mechanism in patients with inverted duplication and terminal deletion. Eur J Hum Genet. 2007:15:548-55

6. Rossi E, Riegel M, Messa J, Gimelli S, Maraschio P, Ciccone R, et al. Duplications in addition to terminal deletions are present in a proportion of ring chromosomes:clues to the mechanisms of formation. J Med Genet. 2008;45:147-54.

7. Kurtas N, Arrigoni F, Errichiello E, Zucca C, Maghini C, D'Angelo MG, et al. Chromothripsis and ring chromosome 22: a paradigm of genomic complexity in the Phelan-McDermid syndrome (22q13 deletion syndrome). J Med Genet. 2018;55(4):269-77.

8. Lee S, Kyun Han D, Cho H, Cho YK, Ma JS. Mosaic ring chromosome 6 in an infant with significant patent Ductus Arteriosus and multiple congenital anomalies. J Korean Med Sci. 2012;27:948-52.

9. Mc Gowan-Jordan J, Simons A, Schmid M. An international system for human cytogenetic nomenclature. Basal: S. Kager; 2016.

10. Bogani D, Willoughby C, Davies J, Kaur K, Mirza G, Paudyal A, et al. Dissecting the genetic complexity of human $6 p$ deletion syndromes by using a region-specific, phenotype-driven mouse screen. Proc Natl AcadSci U S A. 2005;102(35):12477-82. https://doi.org/10.1073/pnas.0500584102.

11. Su PH, Chen JY, Chen SJ, Yang KC. Terminal deletion of chromosome 6q. PediatrNeonatol. 2008;(3):88-93. https://doi.org/10.1016/S18759572(08)60019-4.

12. Guilherme RS, Meloni VFA, Kim CA, Pellegrino R, Takeno SS, Spinner NB, et al. Mechanisms of ring chromosome formation, ring instability and clinical consequences. BMC Med Genet. 2011;12:171.

13. Pace NP, Maggouta F, Twigden M, Borg I. Molecular cytogenetic characterisation of a novel de novo ring chromosome 6 involving a terminal $6 p$ deletion and terminal $6 q$ duplication in the different arms of the same chromosome. MolCytogenet. 2017;10:9. https://doi.org/10.1186/ s13039-017-0311-y.

14. Ciocca L, Surace C, Digilio MC, Roberti MC, Sirleto P, Lombardo A, et al. Array-CGH characterization and genotype-phenotype analysis in a patient with a ring chromosome 6. BMC Med Genet. 2013;6:3. https://doi.org/10. 1186/1755-8794-6-3.
15. Ahzad HA, Ramli SF, Loong TM, Salahshourifar I, Zilfalil BA, Yusoff NM. De novo ring chromosome 6 in a child with multiple congenital anomalies. Kobe J Med Sci. 2010;56:E79-84.

16. Walker ME, Salamon DAL, Milatovich A, Saal HM. Prenatal diagnosis of ring chromosome 6 in a fetus with hydrocephalus. PrenatDiagn. 1996;16:857-61.

17. Kini KR, Van Dyke DL, Weiss L, Logan MS. Ring chromosome 6: case report and review of literature. Hum Genet. 1979;50:145-9.

18. Fried K, Rosenblatt M, Mundel G, Krikler R. Mental retardation and congenital malformations associated with a ring chromosome 6. Clin Genet. 1975;7:192-6.

19. Zhang HZ, Li P, Wang D, Huffs NM, Qumsiyeh M, et al. FOXC1 gene deletion is associated with eye anomalies in ring chromosome 6. Am J Med Genet A. 2004;124A:280-7.

20. Hurd LM, Thacker MM, Okenfuss E, Duker AL, Lou Y, Harty MP, et al. Aneurysmal bone cysts and pathologic fracture associated with supernumerary ring chromosome 6 in two unrelated patients. Am J Med Genet A. 2017. https://doi.org/10.1002/ajmg.a.38498.

21. Andrieux J, Devisme L, Valat AS, Robert Y, Frnka C, Savary JB. Prenatal diagnosis of ring chromosome 6 in a fetus with cerebellar hypoplasia and partial agenesis of corpus callosum: case report and review of the literature. Eur J Med Genet. 2005;199:206.

22. Kara N, Okten G, Guneş SO, Saglam Y, Tasdemir HA, Pinarli FA. An epileptic case with mosaic ring chromosome 6 and $6 q$ terminal deletion. Epilepsy Res. 2008:80(2-3):219-23. https://doi.org/10.1016/j.eplepsyres.2008.03.020.

23. Nishigaki S, Hamazaki T, Saito M, Yamamoto T, Seto T, Shintaku H. Periventricular heterotopia and white matter abnormalities in a girl with mosaic ring chromosome 6. MolCytogenet. 2015;8:54. https://doi.org/10. 1186/s13039-015-0162-3.

24. Hockner M, Utermann B, Erdel M. FauthC,Utermann G, Kotzot D. molecular characterization of a de novo ring chromosome 6 in a growth retarded but otherwise healthy woman. Am J Med Genet. 2008;146A:925-9.

25. Nishi Y, Yoshimura O, Ohama K, Usui T. Ring chromosome 6: case report and review. Am J Med Genet. 1982:12:109-14.

26. Linhares ND, Svartman M, Rodrigues TC, Rosenberg C, Valadares ER. Subtelomeric $6 \mathrm{p} 25$ deletion/duplication: report of a patient with new clinical findings and genotypephenotype correlations. Eur J Med Genet. 2015:58(5):310-8.

27. Miño CP, Benítez J, Ayuso C, Cascos SA. Ring chromosome 6: clinical and cytogenetic behaviour. Am J Med Genet. 1990;35(4):481-3.

28. Carnevale A, Blanco B, Castillo J, Castillo V, Dominguez D. Ring chromosome 6 in a child with minimal abnormalities. Am J Med Genet. 1979:4:271-7.

29. Nam S, Lim JS. Essential role of interferon regulatory factor 4 (IRF4) in immune cell development. Arch Pharm Res. 2016. https://doi.org/10.1007/ s12272-016-0854-1.

30. Nishimura DY, Searby CC, Alward WL, Walton D, Craig JE, Mackey DA, et al. A spectrum of FOXC1 mutations suggests gene dosage as a mechanism for developmental defects of the anterior chamber of the eye. Am J Hum Genet. 2001;68:364-72.

31. Lehmann OJ, Ebenezer ND, Ekong R, Ocaka L, Mungall AJ, Fraser S, et al. Ocular developmental abnormalities and glaucoma associated with interstitial 6p25 duplications and deletions. Invest Ophthalmol Vis Sci. 2002:43:1843-9.

32. Seo S, Kume T. Forkhead transcription factors, Foxc1 and Foxc2, are required for the morphogenesis of the cardiac outflow tract. Dev Biol. 2006;296:421-36.

33. Qi Z, LJB J, Slavotinek A, Yu J. Haploinsufficiency and triploinsensitivity of the same 6p25.1p24.3 region in a family. BMC Med Genet. 2015;8:38. https://doi.org/10.1186/s12920-015-0113-1.

34. Roon WMC, Reid MSJ, Faull RLM, Snell RG. TATA-binding protein in neurodegenerative disease. Neuroscience. 2005;133:863-72.

35. Rooms L, Reyniers E, Scheers S, Luijk RV, Wauters J, Aerschot LV, et al. TBP as a candidate gene for mental retardation in patients with subtelomeric $6 \mathrm{q}$ deletions. Eur J Hum Genet. 2006;(10):1090-6.

36. Eash D, Waggoner D, Chung J, Stevenson D, Martin C. Calibration of $6 \mathrm{q}$ subtelomere deletions to define genotype/phenotype correlations. Clin Genet. 2005;67(5):396-403. https://doi.org/10.1111/j.1399-0004. 2005.00424.x.

37. Conti V, Carabalona A, Pallesi-Pocachard E, Parrini E, Leventer RJ, Buhler E, et al. Periventricular heterotopia in $6 \mathrm{q}$ terminal deletion syndrome: role of the C6orf70 gene. Brain. 2013;136:3378-94. https://doi.org/10.1093/brain/ awt249. 